\title{
A Short Report on the Polymerization of Pyrrole and Its Copolymers by Sonochemical Synthesis of Fluorescent Carbon Dots
}

\author{
Moorthy Maruthapandi and Aharon Gedanken * \\ Bar-Ilan Institute for Nanotechnology and Advanced Materials, Department of Chemistry, Bar-Ilan University, \\ Ramat-Gan 52900, Israel \\ * Correspondence: gedanken@mail.biu.ac.il; Tel.: +972-3-5318315; Fax: +972-3-7384053
}

Received: 23 June 2019; Accepted: 23 July 2019; Published: 26 July 2019

\begin{abstract}
In polymer chemistry, polymerization constitutes the process of the conversion of monomers into polymers using an initiator to form polymeric chains. There are many polymerization techniques and different systems exist by which the polymers are classified. Recently, our group has reported the synthesis of polymers using both carbon dots (CDs) and UV light as initiators. In these reports, the carbon dots were used with or without UV light. The CDs produce free radicals in the presence of UV light, indicating their role as initiators. The CD surface has many unshared or unpaired electrons, making it negatively charged. The present study focuses on the use of CDs for the formation of polymers from monomers containing various functional group. The properties of the synthesized CDs and the polymers obtained from the various monomers were characterized by various analytical techniques, including Fourier-Transform Infrared (FTIR) spectroscopy, X-ray Diffraction (XRD), Thermogravimetric Analysis (TGA) and Solid-State NMR spectroscopy. This polymerization technique is of interest both from the scientific aspect and for its applicative potential. The synthesized polymers were investigated for their various applications.
\end{abstract}

Keywords: carbon dots; sonochemical method; UV-light; polypyrrole; Poly(pyrrole-co-aniline); Poly (Bis(p-aminophenyl) ether-co-pyrrole)

\section{Introduction}

Recently, carbon dots (CDs) have been emerging as new materials demonstrating great potential for use in biomaterial and medical engineering. In the last few decades, carbon dots have begun to feature in such areas as electronic industries, solar and photovoltaic cells, aerospace, catalysis, targeting drug delivery [1-5]. CDs are a type of nanomaterial composed of a carbon core, with oxygen and hydrogen on the circumference of the $5 \mathrm{~nm}$ dots appearing as carboxylic, or carbonyl, or alcohol groups [6-10]. CDs have been used as new cell imaging and drug-delivery nano-platforms due to their outstanding fluorescence, biocompatibility, excellent aqueous solubility, negligible cytotoxicity, easy functionalization, biodegradation ability, and environmental friendliness. CDs have been synthesized by several methods, including microwaves and ultrasonic irradiation [11-17]. The characteristic properties of CDs are partially dependent on the particular carbon-based starting materials, which include sugars, proteins, amino acids, juice carbohydrates, milk, glucose, etc. [12,18-20]. The CDs synthesized sonochemically from polyethylene glycol (PEG-400) provide a high quantum yield (QY) of fluorescence, [21,22] and have been applied in numerous areas of science and technology due their high photoluminescence, biocompatibility, low-cost preparation, no cell cytotoxicity, and high stable fluorescence [5,21,23-29]. Moreover, the synthesis of CDs from PEG produces a good passivating layer on their surface. These sonochemically prepared CDs were used here as an initiator for 
polymerization because they form free radicals in aqueous solution, which leads to their unique functionality and their high potential in many applications $[1,6-8,30-32]$. The free radicals play a main role in the polymerization mechanism [18-20,33]. Sonochemistry usually yields unorganized and perturbed particles having dislocations and vacancies leading to the formation of free radicals in water. This was demonstrated, for example for metal oxide NPs comparing the formation of commercial and sonochemically made products of the same size [34]. The same happens in the current work, where the $\mathrm{CDs}$ prepared sonochemically has yielded $\mathrm{OH}$ radicals. The radicals are detected by EPR when exposed to spin traps [22]. Polypyrrole (PPY) is recognized as a conducting polymer that relies on its electrochemical responsive properties rather than on its chemical structure. PPY offers a potentially useful resource because it possesses optical, magnetic, and electronic properties comparable to those of metals or semiconductors, while also retaining its polymeric structure and properties, such as ease of processing, low toxicity, flexibility, and adjustable electrical conductivity [34-40]. However, the general applications of PPY have been mostly limited to date owing to its poor mechanical properties. In order to improve the mechanical properties, various dopants have been introduced into the polymer using certain strong initiators [39,41-43]. Our novel polymerization of PPY was developed using only CDs as initiator, without any other strong initiators [44-46]. The synthesized polypyrrole has been used as an adsorbent material for various organic dyes and for biological application [47,48].

To date, there have been only a few reports on the synthesis of polymers using CDs and UV light, all of which were reported by our group. The conventional synthesis of the conductive polymer polypyrrole usually employed various strong oxidizing agents as initiators. The best methods by which PPY is polymerized are either through chemical oxidization or electrochemically. There are many initiators that have been used for the polymerization of pyrrole, including ferric chloride, silver nitrate, ammonium persulfate, potassium persulfate, and copper (II) chloride [49-60]. These oxidizing agents, however, dangerous as they can cause eye, nose, throat, lung, and skin irritation upon contact [56]. The persulfate salts also produce asthmatic symptoms. We developed polymerization techniques for the synthesis of PPY and PPY copolymers using the CDs both with and without UV-light. Copolymers of PPY were also prepared from various monomers containing various functional group using CDs as initiators. The CD surface has many unshared or unpaired electrons, making it negatively charged [61-63]. During the course of the reaction, the positively charged pyrrole is attracted to the carbon dots, prior to the polymerization reaction. The reflux method was used to synthesize the copolymer of polypyrrole within $24 \mathrm{~h}$ without UV light [64]. The UV light promoted free radical generation, replacing the use of thermal heating to accomplish the polymerization. The present article reports on the synthesis of PPY and its copolymers using CDs, as well as discussing the coating of the $\mathrm{CD}$ onto a glass slide that served as a substrate for the polymerization of PPY.

\section{Experimental Section}

\subsection{Preparation of $C D s$}

$30 \mathrm{~mL}$ of PEG-400 was placed in a $50 \mathrm{~mL}$ beaker in an oil bath and heated to $70{ }^{\circ} \mathrm{C}$. The tip of an ultrasonic transducer was immersed in the PEG-400 and sonication was carried out for $3 \mathrm{~h}$ at $65 \%$ amplitude [21,22].

\subsection{CDs Coated on Glass Slides}

In parallel, CDs were produced and coated on glass slides. The process was identical to that described above except that the sonication beaker contained a glass slide and sonication was continued for $60 \mathrm{~min}$ at $25^{\circ} \mathrm{C}$ in order to deposit the preformed CDs onto the glass slide. The glass slides were washed with water and dried in an oven at $50{ }^{\circ} \mathrm{C}$ for $1 \mathrm{~h}$ under ambient atmosphere. The free CDs observed on the slides were utilized for the synthesis of the polymer. The ultrasonic waves, and particularly the micro-jets formed after the collapse of the acoustic bubbles, caused the embedding of the CDs formed on the glass [44]. After the synthesis, the polymer was washed several times with 
water and ethanol to remove unreacted CDs. The lifetime of the CDs containing free electrons is short and their quantity is much smaller than the amount of the polymer. Sonochemically prepared CDs initiated polymerization is displays in Scheme 1.

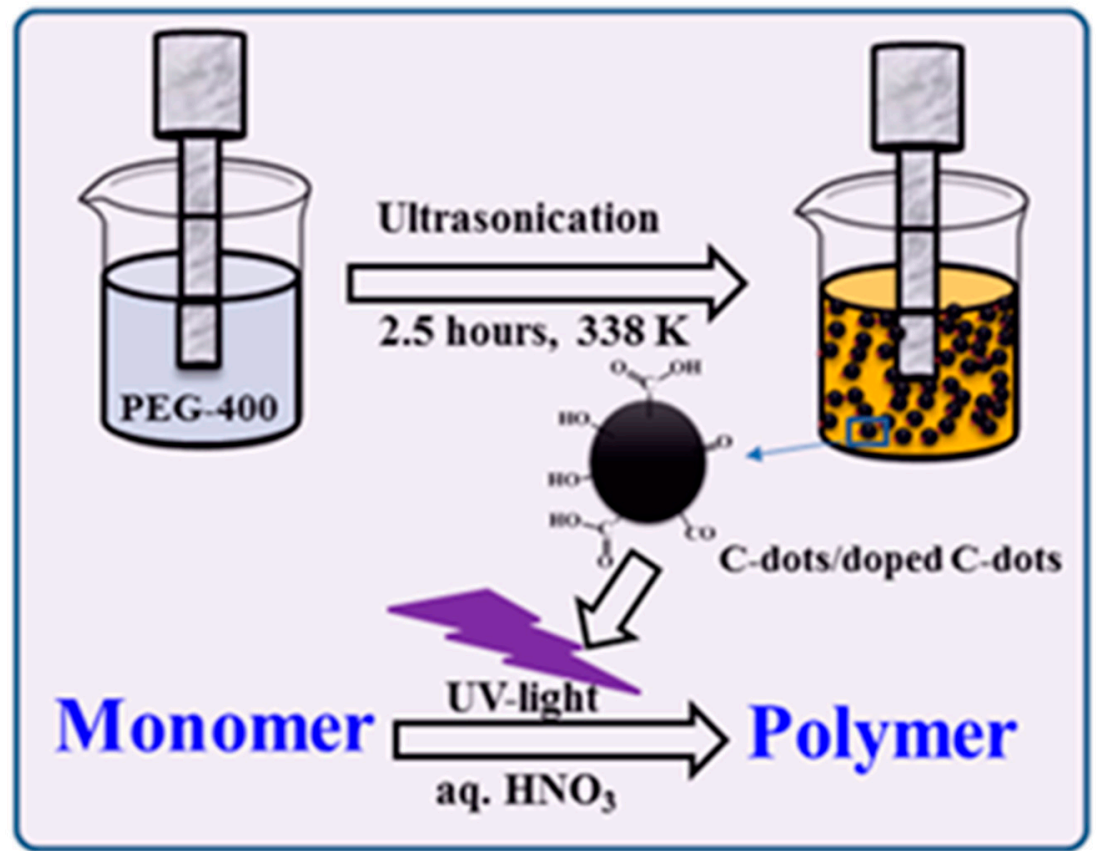

Scheme 1. Sonochemically prepared carbon dots (CDs) for polymerization.

\subsection{Synthesis of Polypyrrole and Its Copolymer by CDs}

Pyrrole $(1.0 \mathrm{~g})$ was mixed in $30 \mathrm{~mL}$ of $1 \mathrm{M}$ nitric acid in a $100 \mathrm{~mL}$ beaker at room temperature. A $3 \mathrm{~mL}$ aqueous solution containing $9 \mathrm{mg}$ of CDs was then added. A similar process was carried out to prepare polyaniline using CDs coated onto a glass slide rather than a CD dispersion in water. To activate the reaction, the solution was kept under UV light (USV-18 EL series UV lamp and 8-Watt, $365 \mathrm{~nm}$ wavelength) for 3 days, after which we observed the precipitation of blackish-brown solids, which we collected by filtration. These solids were washed several times with distilled water and dried at room temperature. The polypyrrole was also synthesized using different molar concentrations of nitric acid and pyrrole [44]. The Scheme 2 shows the chemical reaction of polypyrrole.

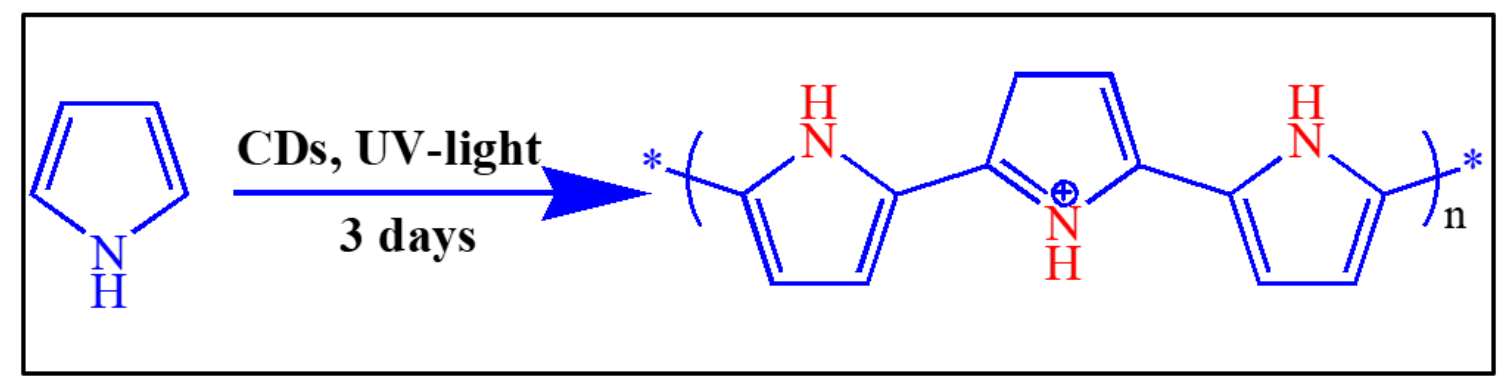

Scheme 2. The chemical reaction of polypyrrole.

\subsection{Poly(pyrrole-co-aniline)}

Pyrrole $(1.0 \mathrm{~g})$ and aniline $(1.0 \mathrm{~g})$ were mixed in $30 \mathrm{~mL}$ of $1 \mathrm{M}$ nitric acid in a $100 \mathrm{~mL}$ beaker at room temperature. To this, $5 \mathrm{~mL}$ of an aqueous solution containing $15 \mathrm{mg}$ of CDs was added. The polymerization reaction was stimulated by illumination with UV light for three days, after which a blackish-brown solid was obtained and collected by filtration, washed several times with distilled water, 
and dried at room temperature [44]. The chemical reaction of poly(pyrrole-co-aniline) is illustrates in Scheme 3.

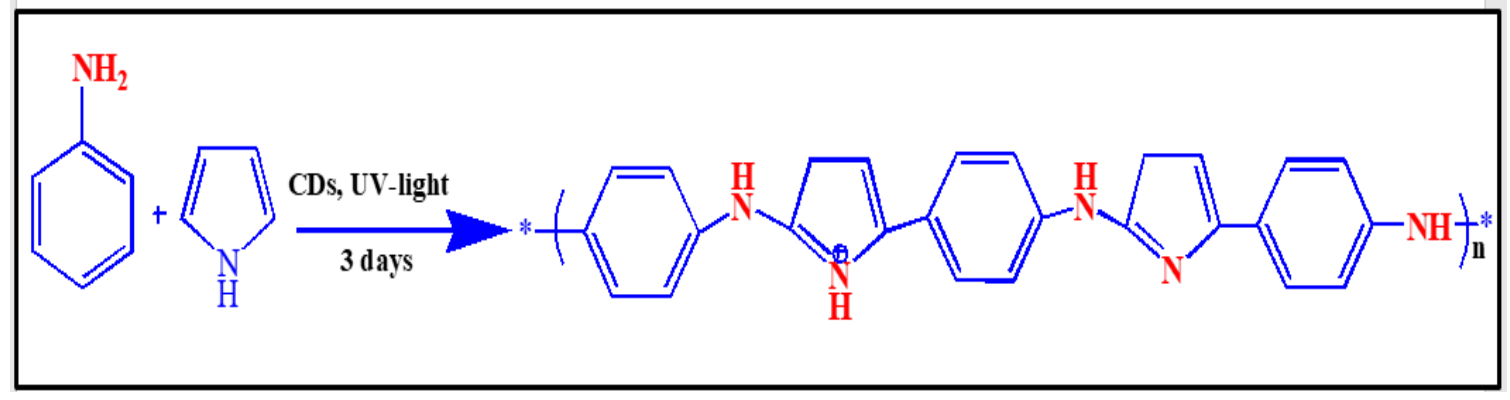

Scheme 3. The chemical reaction of poly(pyrrole-co-aniline).

\subsection{Synthesis of Poly (Bis(p-aminophenyl)ether-co-pyrrole)}

Bis(p-aminophenyl) ether ( $0.6 \mathrm{~g}, 3 \mathrm{mmol})$, pyrrole $(0.6 \mathrm{~g}, 10 \mathrm{mmol}), \mathrm{CD}$ solution $(3 \mathrm{~mL}, 9 \mathrm{mg})$, acetonitrile $(15 \mathrm{~mL})$, nitric acid $(1.5 \mathrm{~mL})$, and distilled water $(10 \mathrm{~mL})$ were mixed, after which the color of the monomer changed from a white solid to a purple solution. The reaction mixture was then mixed well and refluxed in an oil bath for $24 \mathrm{~h}$ at $90^{\circ} \mathrm{C}$ under ambient environment. The reaction mixture was then cooled to room temperature and poured into a beaker filled with ice. The dark brown solids that precipitated were collected by filtration, washed several times with distilled water, and dried at room temperature [64]. The chemical reaction of (Bis(p-amino phenyl) ether-co-pyrrole) is demonstrates in Scheme 4.

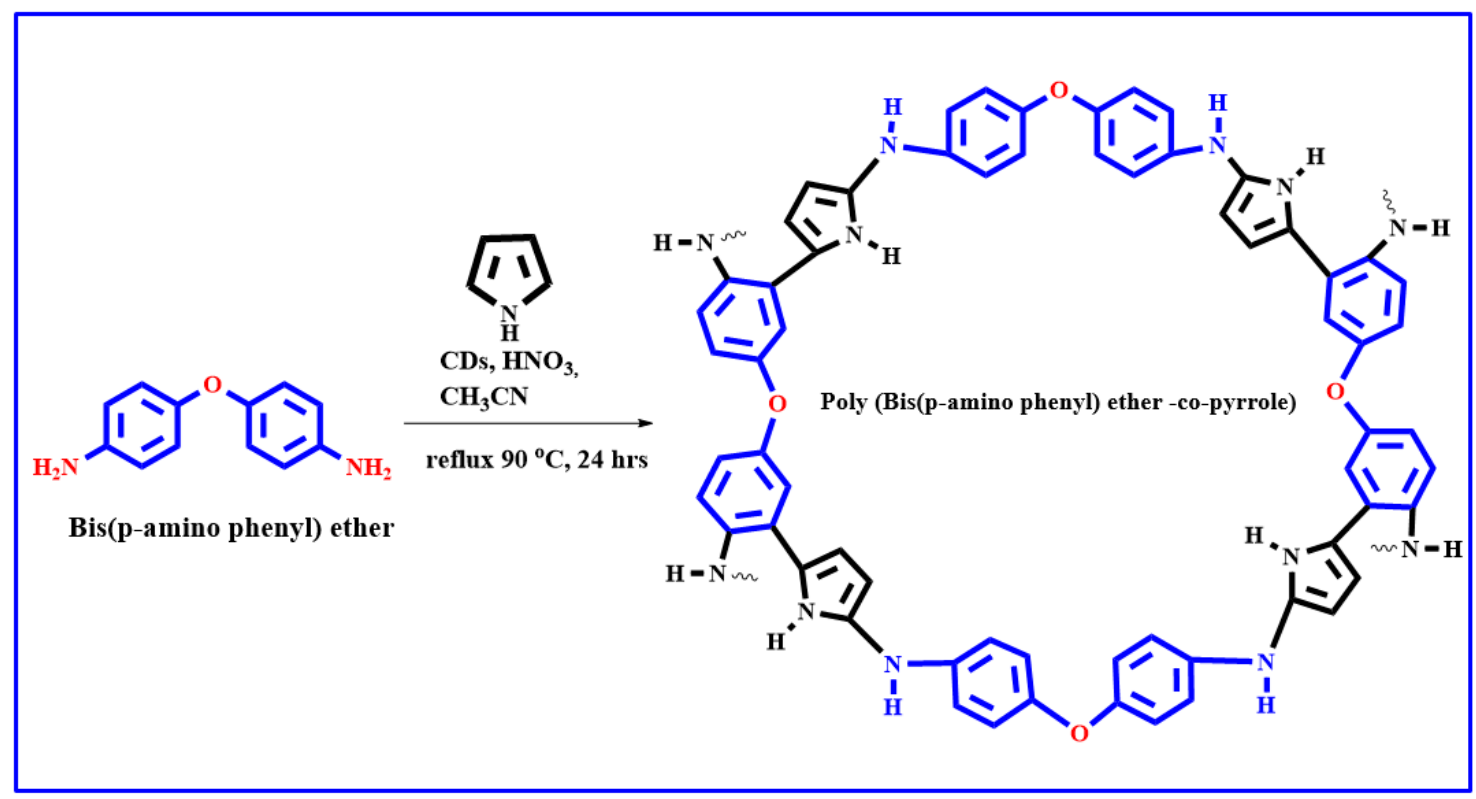

Scheme 4. The chemical reaction of Poly (Bis(p-aminophenyl) ether-co-pyrrole).

\section{Physical Characterization of CDs as Initiator}

Characterization of the properties of the prepared CDs, used as an initiator for the different polymerization processes, is provided below. High-resolution transmission electron microscopy (HR-TEM) images of the CDs revealed them to be spherical in shape, with a rather narrow size distribution (Figure 1a). The average size of the CDs was about $\sim 10 \mathrm{~nm}$, which is in contrast to our previously-prepared CDs. CDs embedded on the glass slide are displayed in Figure 1b. The particles on the glass slide present a larger size range $(17-50 \mathrm{~nm})$ than those formed in the solution. This larger 
size appears to be due to the sonochemical coating bombarding the already-coated surface and adding CDs to the first existing layer and thus enlarging them. The detailed characterizations of XRD, EPR, Zeta potential values, and XPS for CDs were already provided by our group [44].
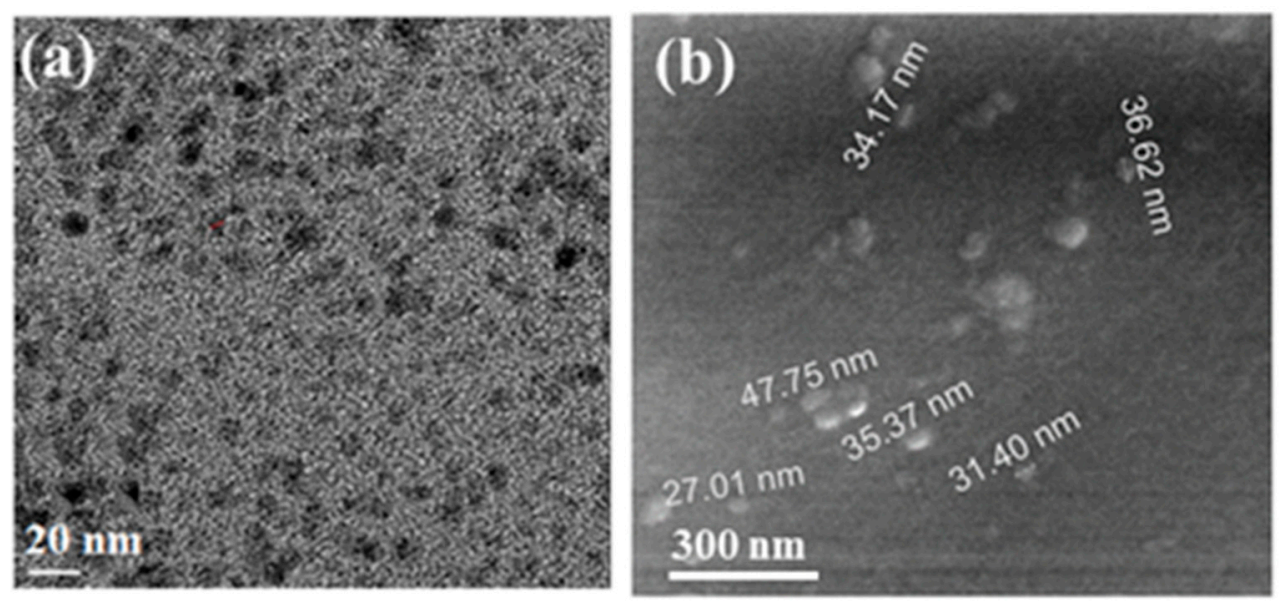

Figure 1. HRTEM images of (a) CDs that were separated from the PEG 400 suspension and (b) deposited onto a glass side. [44].

Recently, we reported the formation of ultrafine CDs by means of ultrasonic cavitation in PEG-400. Characterization of the products was performed employing various methods. HRTEM images (Figure $2 \mathrm{a}$ ) of the CDs reveal them to possess a spherical shape with a narrow size distribution $(\sim 6 \mathrm{~nm})$. The fluorescence emission of the CDs found in the supernatant was spread over the 420-610 nm range (Figure 1b), with the excitation wavelengths being between 330 and $490 \mathrm{~nm}$. The d-spacing of CDs was estimated from the HRTEM and selected area electron diffraction patterns and was found to be $0.21 \mathrm{~nm}$.
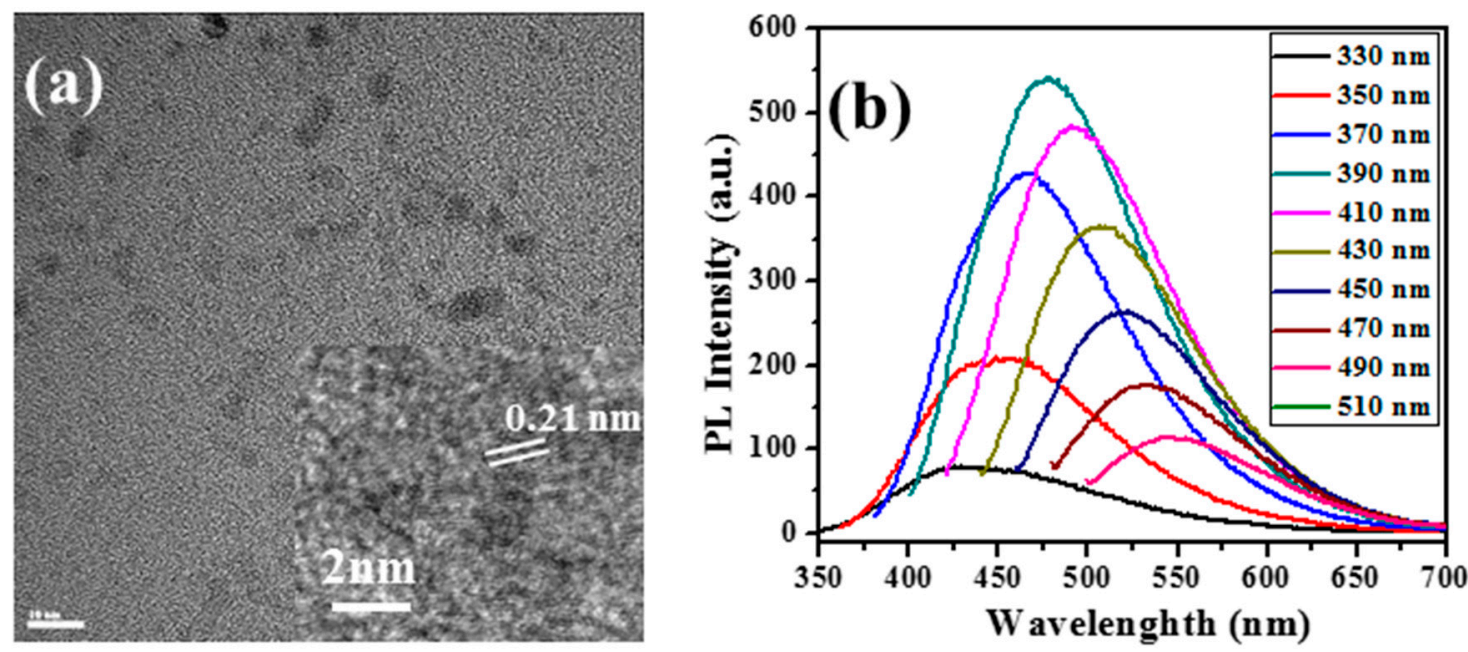

Figure 2. (a) HRTEM images of the CDs (Inset: lattice fringes of CDs); (b) fluorescence spectra at different excitation wavelengths [45].

Figure 3a presents images of a CD dispersion taken under ambient light and under irradiation with a hand-held, long-wave TLC lamp (365 nm excitation), highlighting the strong, blue fluorescence of the CD dispersion resulting from such excitation. The UV-Vis absorption spectra of the CDs are displayed in Figure 3b. The strong absorption bands of CDs at 246 and $360 \mathrm{~nm}$ are due to the $\pi-\pi^{*}$ electron transition and graphitic nature of the carbon material, respectively. 

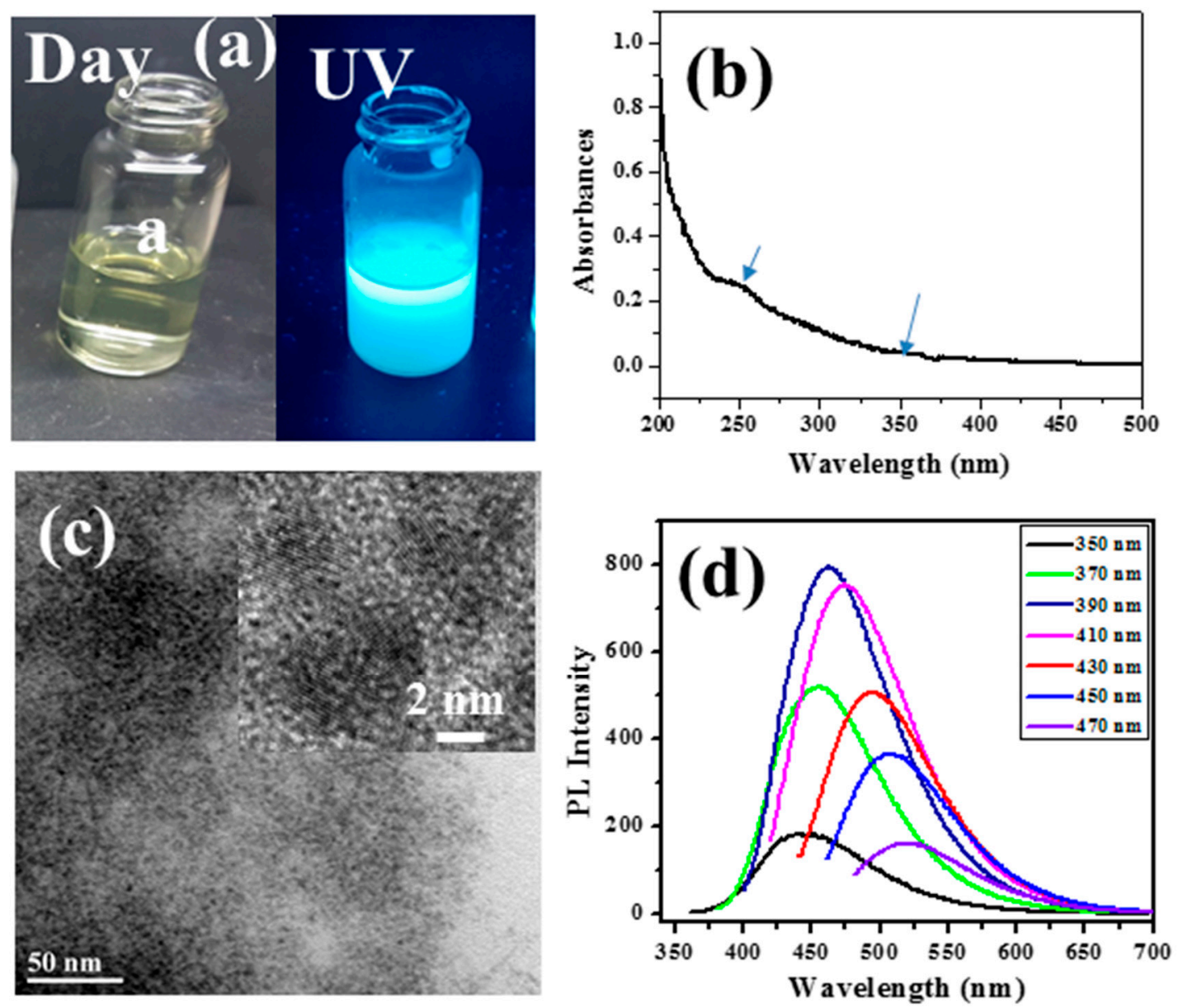

Figure 3. Characterization of CD products: (a) Optical images of the CD dispersion under ambient light and under UV-light irradiation; (b) UV-visible absorption spectrum of the CD dispersion, with two main maxima indicated by blue arrows; (c) HRTEM images of the CD; and (d) Fluorescence spectra of the CD solution with excitation under a diversity of dissimilar wavelengths [64].

A magnified HRTEM image (Figure 3c, inset) of individual CDs demonstrates that the lattice plane of CDs is $0.21 \mathrm{~nm}$ and ties with the graphite facet (100), in agreement with previous reports on $\mathrm{CD}$ microscopic images [26]. The fluorescence emission spectra were recorded at various excitation wavelengths (330-470 $\mathrm{nm}$ ) and maximum emission from such excitations were observed in the range of 420-600 nm. Figure 3d displays the typical fluorescence spectra of CDs produced from PEG-400 following the sonication treatment.

\subsection{Polypyrrole}

The formation of polypyrrole was confirmed by XRD, FT-IR and TGA (Figure 4). The X-ray diffraction of polypyrrole displayed in Figure $4 \mathrm{a}$, a broadband around $2 \theta=13^{\circ}-45^{\circ}$ due to being parallel to the polypyrrole structure and perpendicular to the polymer chain. The XRD pattern reveals the synthesized polypyrrole to be amorphous in nature. The FT-IR spectrum of polypyrrole shows in Figure $4 \mathrm{~b}$. The FT-IR spectrum reveals a broadband around $3261 \mathrm{~cm}^{-1}$ due to N-H stretching vibration. The peak at $1574 \mathrm{~cm}^{-1}$ is due to the $\mathrm{C}=\mathrm{C}$ in-ring stretching vibration and the band at $1130 \mathrm{~cm}^{-1}$ is due to the $\mathrm{C}-\mathrm{N}$ stretching vibration. The bands at 1308 and $1078 \mathrm{~cm}^{-1}$ are due to the $\mathrm{C}-\mathrm{H}$ in-plane vibration. The thermal stability of the synthesized polypyrrole is provided in Figure 4c. The TGA analysis displays three stages of weight loss: the first stage is minor and the second and third are major weight loss [44]. 

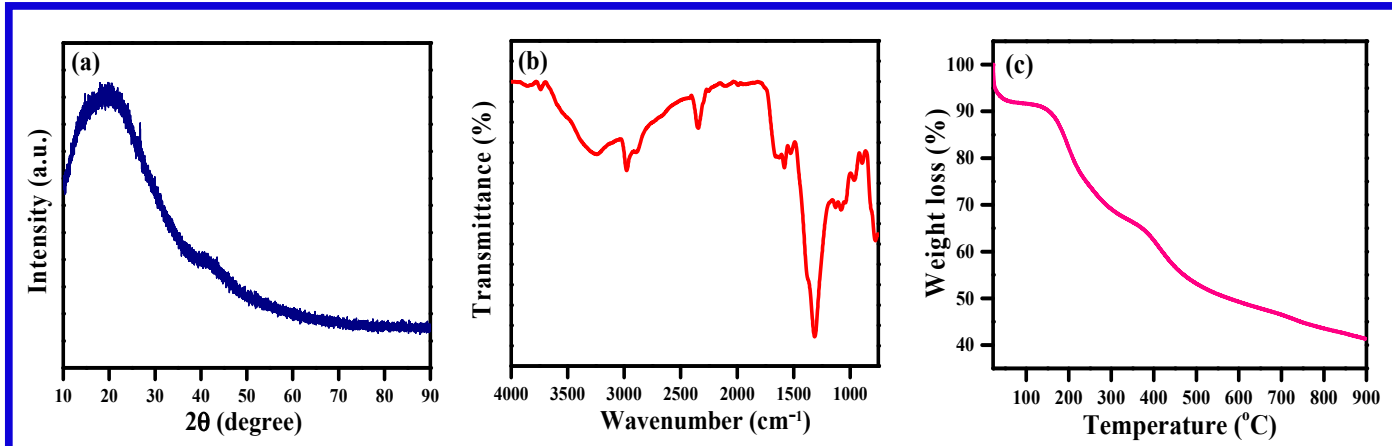

Figure 4. (a) X-ray diffractogram and (b) FT-IR of polypyrrole obtained from the polymerization of pyrrole, and (c) TGA of polypyrrole.

The particle size distribution of the polypyrrole was measured by dynamic light scattering (DLS). Two different populations of particle size distribution were found: $75 \%$ of the particles were micron-size, ca. $1000-1600 \mathrm{~nm}$; and $25 \%$ were nano-size, ca. $600-900 \mathrm{~nm}$. The SEM image shows particles of 2-7 $\mu \mathrm{m}$. The difference between the SEM and the DLS results from the large micron size particles in the SEM being due to the aggregation of particles. A careful look at Figure $5 b$ reveals even smaller particles.

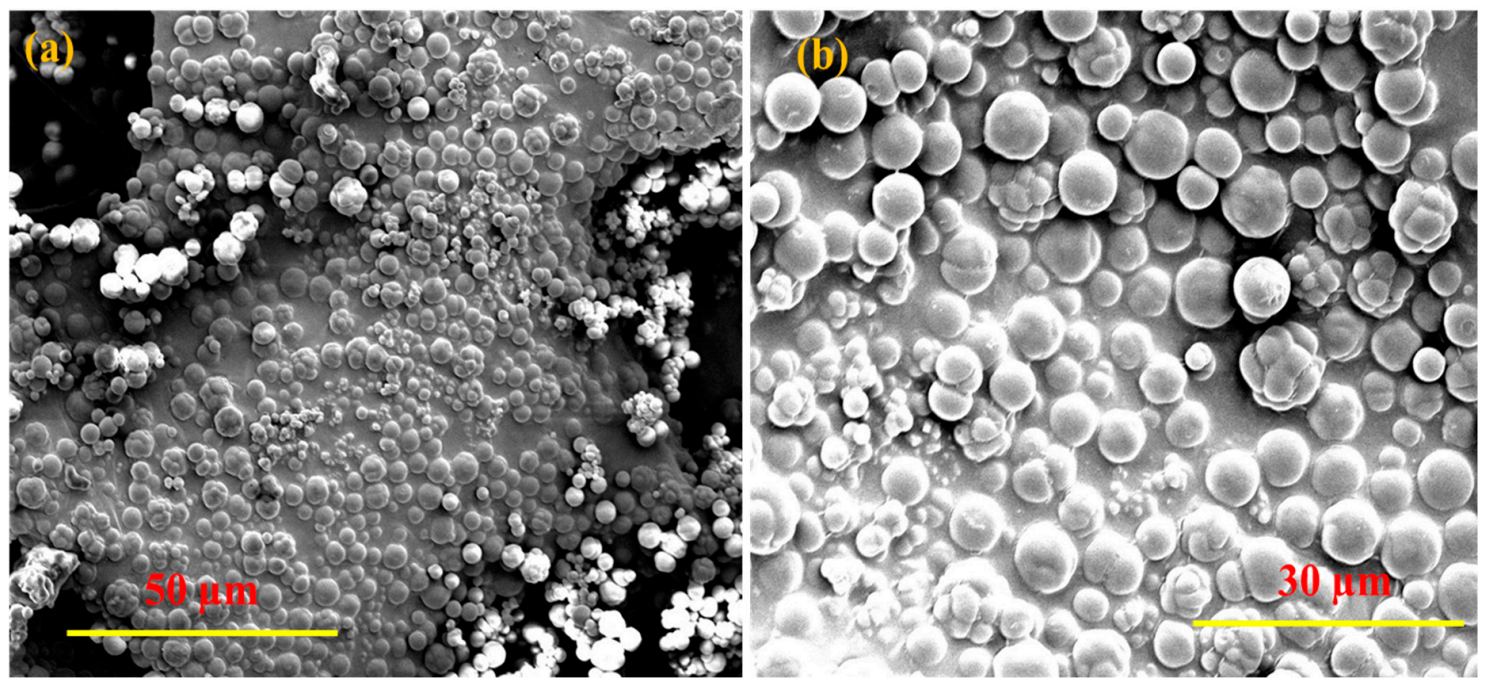

Figure 5. (a,b) SEM micrograms of polypyrrole under different magnification.

In order to confirm successful polymerization, the ${ }^{13} \mathrm{C}$ solid-state NMR was analyzed. The spectrum (Figure 6) is displays four broad bands at 110,122,126,129 ppm and one shoulder peak at $142 \mathrm{ppm}$. The peaks at $122 \mathrm{ppm}$ and 126 are assigned to carbon C-1 and C-2, respectively, while the peak at $110 \mathrm{ppm}$ originates from protonated C-3 and non-protonated C-7 carbon of the quinoid ring in the polypyrrole chain. The peak around $129 \mathrm{ppm}$ is attributed to the protonated C- 6 and C-4 and the non-protonated C-4 carbons. 


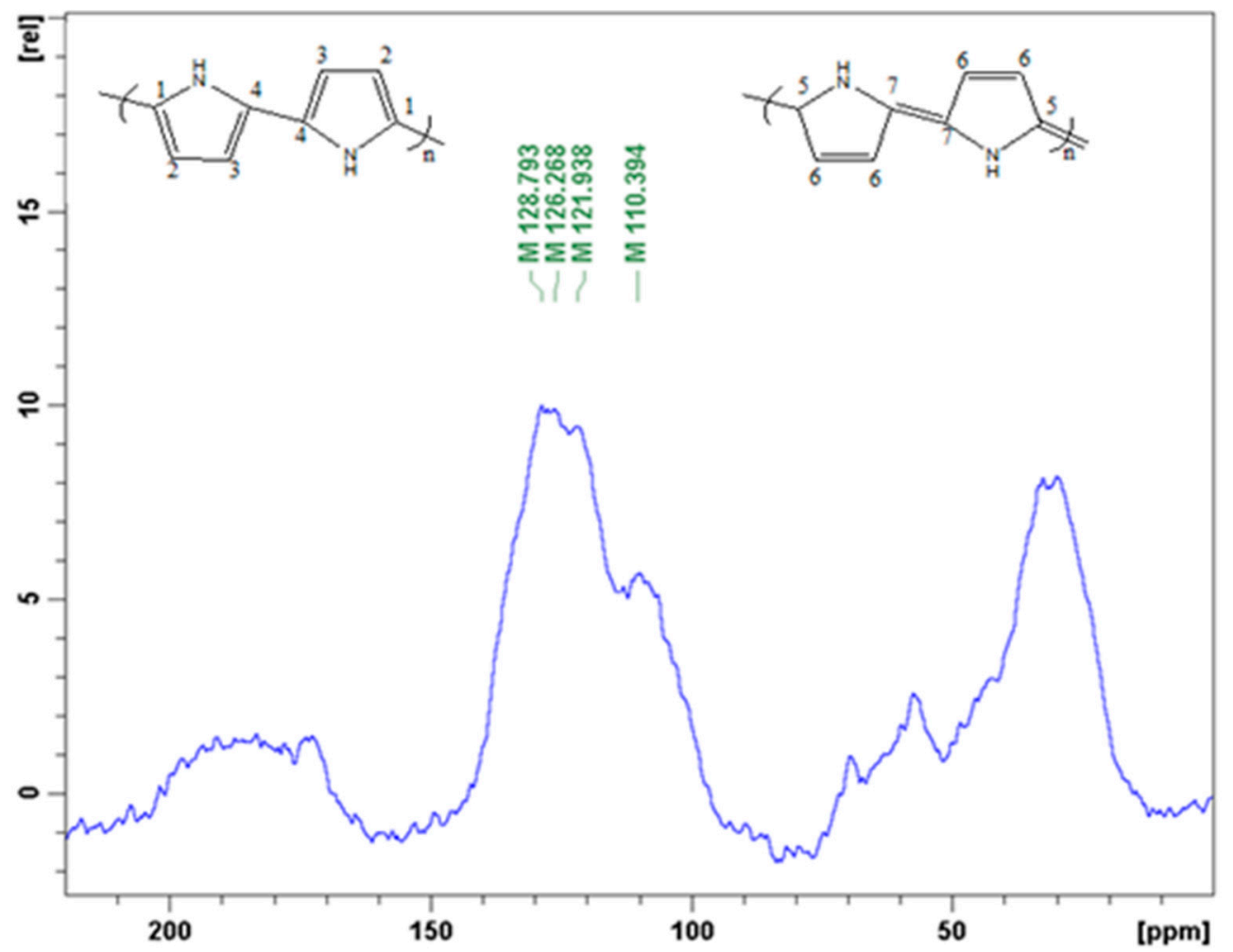

Figure 6. Solid state ${ }^{13} \mathrm{C}-\mathrm{NMR}$ spectrum of polypyrrole.

\subsection{Poly(pyrrole-co-aniline)}

X-ray diffractograms of poly(pyrrole-co-aniline) are given in Figure 7a. A broad peak around $2 \theta=18$ to 40 degrees, indicating the formation of the repeated unit of both the monomers in the polymer chain, demonstrates that the polymer structure is highly associated. The broad peak is evidence that the formation of poly(pyrrole-co-aniline) is amorphous in nature. The IR spectrum for poly(pyrrole-co-aniline) is provided in Figure $7 \mathrm{~b}$. The FT-IR shows a broadband at $3255 \mathrm{~cm}^{-1}$, corresponding to the $\mathrm{N}-\mathrm{H}$ stretching vibration. The aromatic $\mathrm{C}-\mathrm{H}$ stretching vibration band appears at $2984 \mathrm{~cm}^{-1}$ and the peaks at 1572 and $1486 \mathrm{~cm}^{-1}$ are attributed to the $\mathrm{C}=\mathrm{C}$ stretching mode of the benzenoid and quinoid rings. The peak at about $1170 \mathrm{~cm}^{-1}$ is due to the $\mathrm{C}-\mathrm{N}$ stretching vibration and the peak at $1190 \mathrm{~cm}^{-1}$ corresponds to the $\mathrm{N}=$ Quinoid-N+ stretching vibration, respectively [44].

TGA of the Poly(pyrrole-co-aniline) shows a three-step weight-loss performance in Figure 7c. The first major weight loss of $5 \%$ occurs within the temperature range of $70-120{ }^{\circ} \mathrm{C}$ and is due to the removal of moisture or loss water from the polymer; the second major weight loss of around $32 \%$ occurs at around $212-490^{\circ} \mathrm{C}$ and is due to with removal of small oligomers; the third major weight loss is $22 \%$ within a range of $455-720^{\circ} \mathrm{C}$, and is due to the decomposition of the polymer. The morphology of the poly(pyrrole-co-aniline) was examined by SEM. Figure 7e shows that poly(pyrrole-co-aniline) is formed as irregular shapes, ca. $400-500 \mathrm{~nm}$, while the 10-micron size particles in the SEM are due to the aggregation of the particles. Confirmation of the poly(pyrrole-co-aniline) product was established using ${ }^{13} \mathrm{C}$ solid-state NMR in a cross-polarization magic angle-spinning mode. The ${ }^{13} \mathrm{C}$ solid-state NMR spectrum for the poly(pyrrole-co-aniline) is given in Figure 7d. It comprises a broad peak, centered at $127 \mathrm{ppm}$, and companied by a few peaks that appear as shoulders The spectral features all correspond to the aromatic carbons of the poly(pyrrole-co-aniline) backbone. The spectrum demonstrates six broad resonances which can be observed at 116 ppm (shoulder), 138.0, 146.1, 154.5, and $164.0 \mathrm{ppm}$. The peak at $164 \mathrm{ppm}$ originates from protonated and non-protonated carbons of the quinoid part of the poly(pyrrole-co-aniline) structure. 

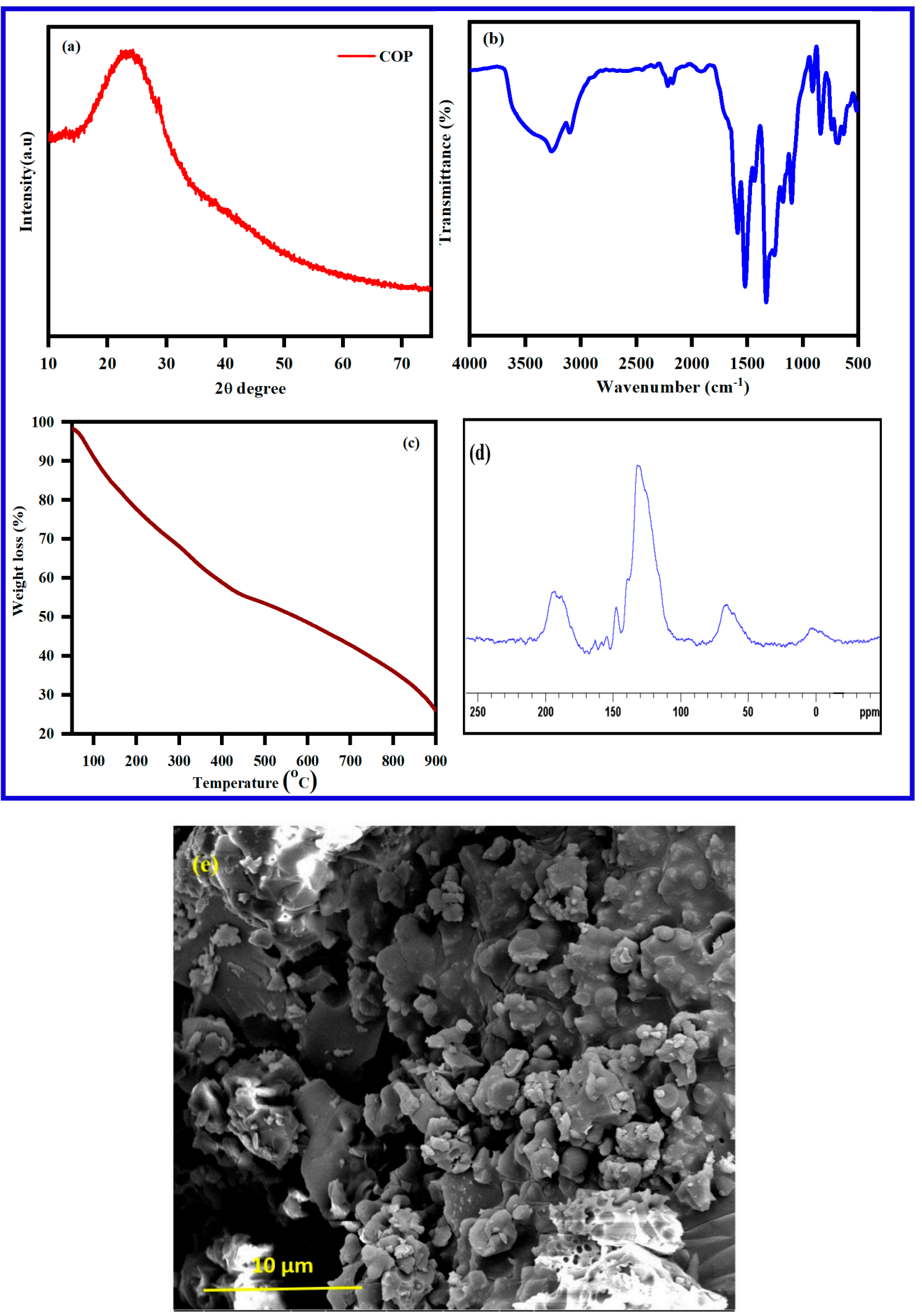

Figure 7. (a) X-ray diffractogram and (b) FT-IR of polypyrrole obtained from the polymerization of (c) TGA of polypyrrole, (d) solid state ${ }^{13} \mathrm{C}-\mathrm{NMR}$ spectrum, and (e) SEM image of poly(pyrrole-co-aniline). 


\subsection{Poly (Bis(p-aminophenyl)ether-co-pyrrole)}

The FTIR spectrum poly (Bis(p-aminophenyl)ether-co-pyrrole) is displayed in Figure 8a as follows: broad peak at $3351 \mathrm{~cm}^{-1}$ is assigned to the $\mathrm{N}-\mathrm{H}$ stretching vibration; an aromatic $\mathrm{C}=\mathrm{C}-\mathrm{H}$ stretching vibration at $3074 \mathrm{~cm}^{-1}$; peaks at 1605 and $1501 \mathrm{~cm}^{-1}$, due to the aromatic $\mathrm{C}=\mathrm{C}$ stretching vibration; peaks around $1340 \mathrm{~cm}^{-1}$ which are due to the $\mathrm{C}-\mathrm{N}$ stretching vibration; a peak at $1246 \mathrm{~cm}^{-1}$, is due to the ether $\mathrm{C}-\mathrm{O}$ stretching vibration; and a peak at $830 \mathrm{~cm}^{-1}$, is assigned to the out-of-plane bending vibration of an amine group. A summary of all significant IR peaks and the corresponding structural evidence is given in Table 1 [64].

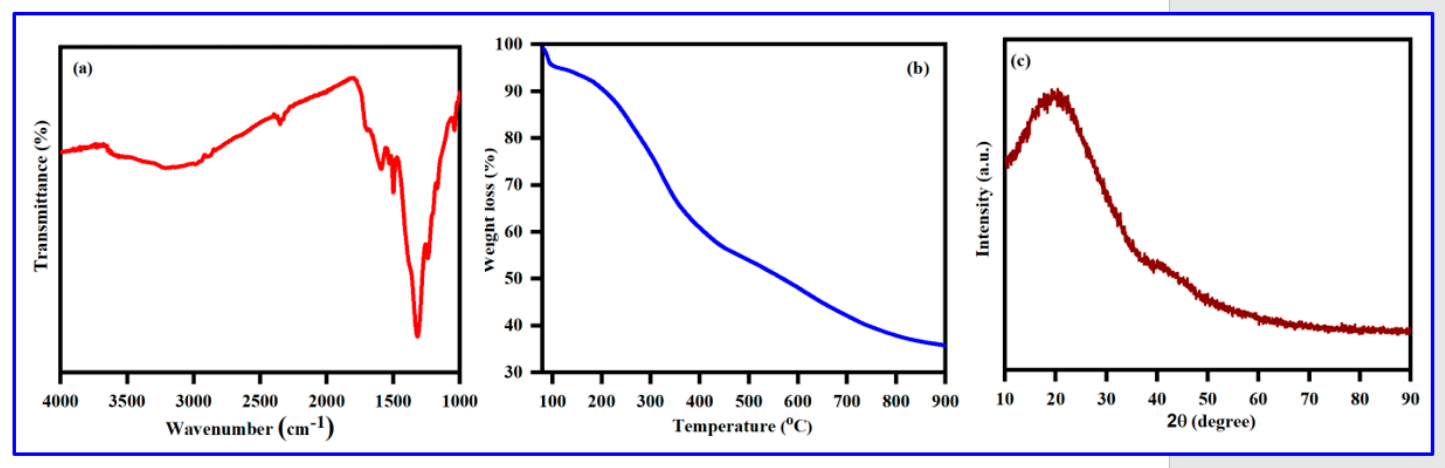

Figure 8. (a) FT-IR- spectrum, (b) TGA analysis, and (c) X-ray diffractogram of Poly (Bis(p-amino phenyl)ether-co-pyrrole).

Table 1. Key peaks in the IR absorption frequency region of Poly (Bis(p-aminophenyl)ether-co-pyrrole) and the corresponding functional groups.

\begin{tabular}{cc}
\hline Poly (Bis(p-aminophenyl)ether-co-pyrrole) & Major Functional Group \\
\cline { 1 - 2 } Absorption Frequency Region $\left.\mathbf{( c m}^{-\mathbf{1}}\right)$ & \\
\hline 3351 & $\mathrm{~N}-\mathrm{H}$ (stretching vibration) \\
3074 & $\mathrm{C}=\mathrm{C}-\mathrm{H}$ (aromatic stretching vibration) \\
1605 and 1501 & $\mathrm{C}=\mathrm{C}$ (stretching vibration) \\
1340 & $\mathrm{C}-\mathrm{N}$ (stretching vibration) \\
1246 & $\mathrm{C}-\mathrm{O}$ ether (stretching vibration) \\
830 & out of plane bending vibration of amine \\
\hline
\end{tabular}

The TGA weight loss of Bis(p-aminophenyl) ether exhibited three dissimilar weight loss stages (Figure 8b): (1) Minor weight loss $(4 \%)$ at $97-135^{\circ} \mathrm{C}$, due to the evaporation of moisture and water molecules; (2) $12 \%$ weight loss between $468-664^{\circ} \mathrm{C}$, attributed to the thermal removal of oligomers; and (3) final weight loss above $721^{\circ} \mathrm{C}$ due to the thermal decomposition of the polymer.

Further demonstration of the crystalline nature of the successful polymer was achieved by XRD analysis, with the XRD spectrum of Poly (Bis(p-aminophenyl) ether-co-pyrrole) given in c. A broad peak around $2 \theta=13.4^{\circ}-26.9^{\circ}$ can be ascribed to the repeated units of pyrrole. The XRD spectrum shows that the copolymer is amorphous in nature, as a highly crystalline polymer would display much sharper peaks. A morphological study of the solid-state polymer was conducted using scanning electron microscopy (SEM), with SEM images of Poly (Bis(p-aminophenyl) ether-co-pyrrole) given in Figure 9a. The SEM image of Poly (Bis(p-aminophenyl)ether-co-pyrrole) reveals agglomerated particles with irregular spherical shapes and a broad range of diameters between 800 and $1500 \mathrm{~nm}$. 


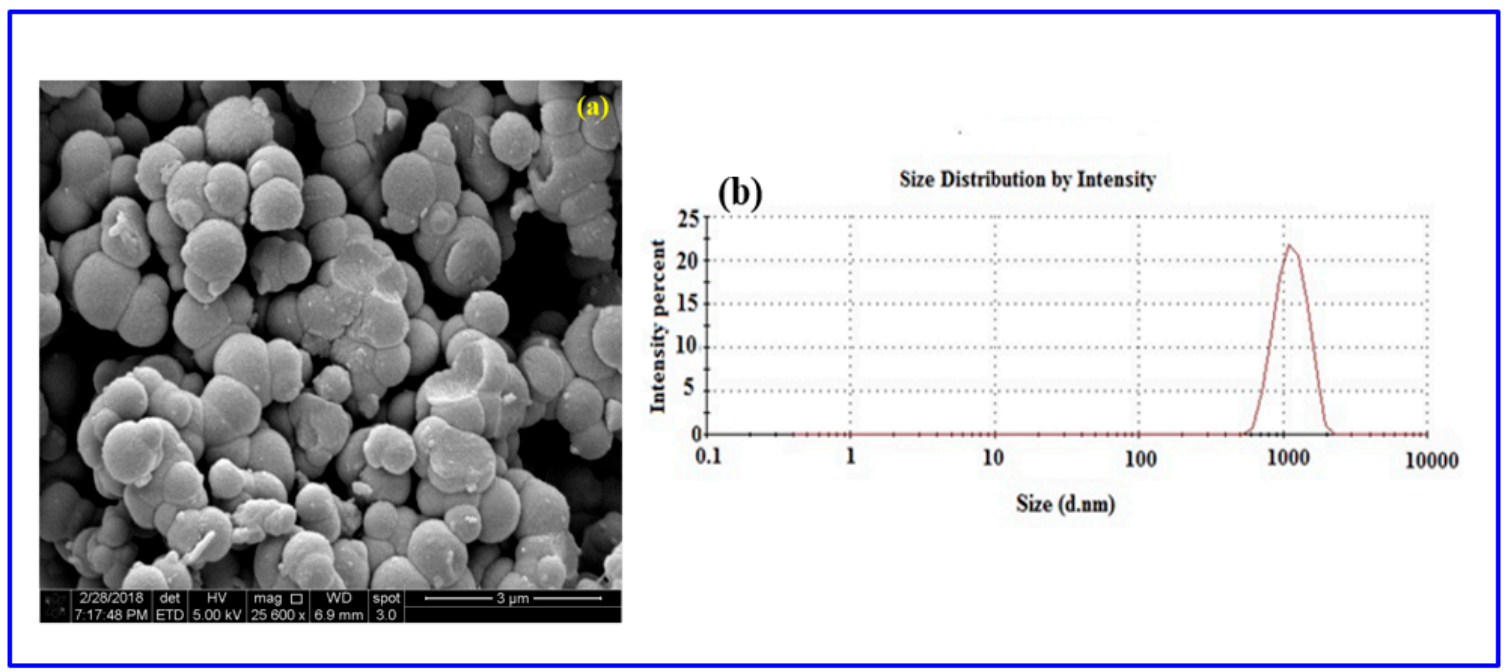

Figure 9. (a) SEM image and (b) DLS measurement of Poly (Bis(p-aminophenyl)ether-co-pyrrole).

The particle size distribution of the Poly (Bis(p-aminophenyl)ether-co-pyrrole) was analyzed by dynamic light scattering (Figure 9a). The particle size diameters ranged from 600 to $2010 \mathrm{~nm}$. The DLS analysis revealed the copolymer of Poly (Bis(p-aminophenyl)ether-co-pyrrole) to possess a macro-nano particle size distribution. The polydispersity of the copolymer with dispersity indices of less than 1.0, evidences the particulate nature of the polymers and strongly signifies the good processability of copolymer dispersions [59].

The successful copolymerization was confirmed by ${ }^{13} \mathrm{C}$ solid-state NMR. The solid-state NMR spectrum Poly (Bis(p-aminophenyl) ether-co-pyrrole) (Figure 10) displays a peak "a" at $153.3 \mathrm{ppm}$ due to the carbon singly-bound to oxygen: and a peak " $\mathrm{b}$ " at $144.1 \mathrm{ppm}$ attributed to the carbon singly-bound to nitrogen. The peak " $\mathrm{c}$ " at $136 \mathrm{ppm}$ is due to the carbon, which is part of the C-N bond between the Bis(p-aminophenyl) ether subunit and the pyrrole ring. Peaks " $\mathrm{d}$ " and "g", at 123.5 and $106.3 \mathrm{ppm}$, are assigned to the aromatic pyrrole carbons. Finally, peaks " $\mathrm{e}$ " and " $\mathrm{f}$ " indicate that the peaks at 121.1 and $118.3 \mathrm{ppm}$ are attributed to the aromatic carbons of Bis(p-aminophenyl) ether in the copolymer unit.

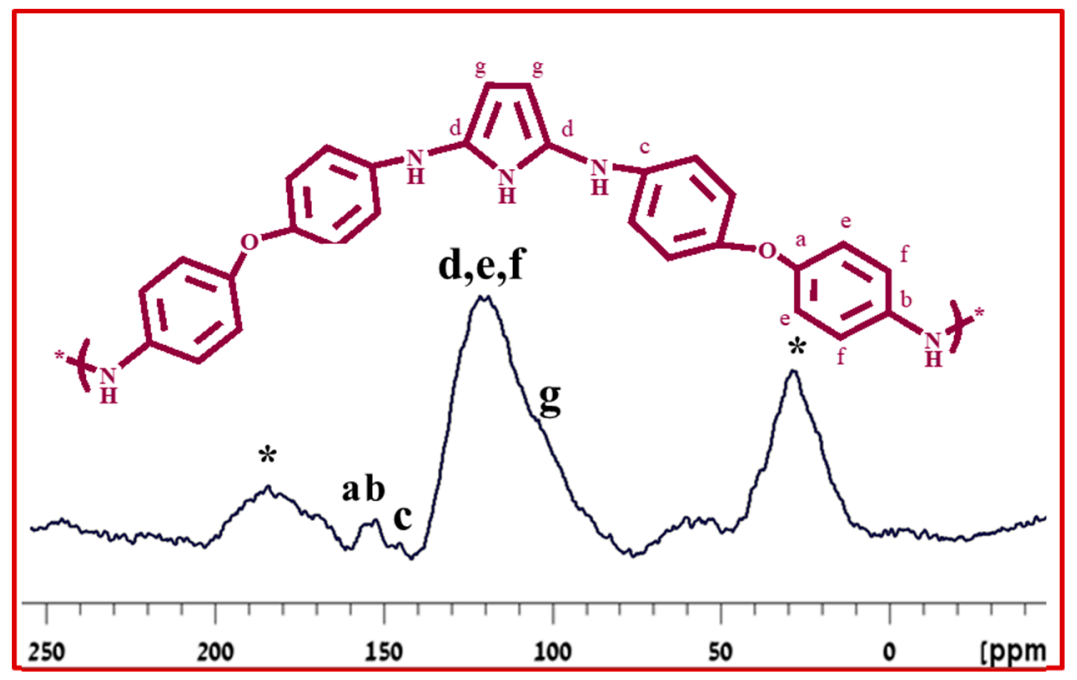

Figure 10. Solid-state ${ }^{13} \mathrm{C}-\mathrm{NMR}$ spectrum of Poly (Bis(p-aminophenyl) ether-co-pyrrole). 


\section{Mechanism for Polymerization}

The polymerization mechanism is supported by CDs and UV light. The dots have an unshared pair of electrons on their surface and are carry negative charges $[21,31,61,63]$. The amine group of the aniline is transformed into the protonated form by the nitric acid. The reason for choosing the high concentration of nitric acid (1-4 M) is that it can efficiently react with base, forming Phenyl ammonium ion, $\left(\mathrm{C}_{6} \mathrm{H}_{5} \mathrm{NH}_{3}+\right)$ at room temperature, this ion can easily react with $\mathrm{CDs}$. Another argument is that the high concentration of the acid can accelerate both the oxidation and the acidification of the amine group. Both influence thermodynamic and kinetics, favor the high concentration of the acid. Electron negative charges on the CDs are adsorbed to the positively charged of the aniline cations, through electrostatic interactions. The role of the UV light in this reaction is the activation of aniline, which enables more aniline molecules to form the protonated species. This is well known and reported recently in the literature [57]. Carbon dots were shown to produce $\mathrm{OH}$ radicals in water. The $\mathrm{OH}$ radicals remove one hydrogen, forming $\mathrm{H}_{2} \mathrm{O}$. A radical $\mathrm{NH}_{2}+$ group is left on the aromatic group. In the next stage, a proton is removed when two of these radicals interact leading to the formation of the polymer. Thus the oxidizing agent is the $\mathrm{OH}$ radical. The UV light assists in the formation of the $\mathrm{OH}$ radicals [22]. The formation of more free radical is caused by the photoexcitation of CDs. The mechanism for the formation of polyaniline by carbon dot is shows in Scheme 5 .

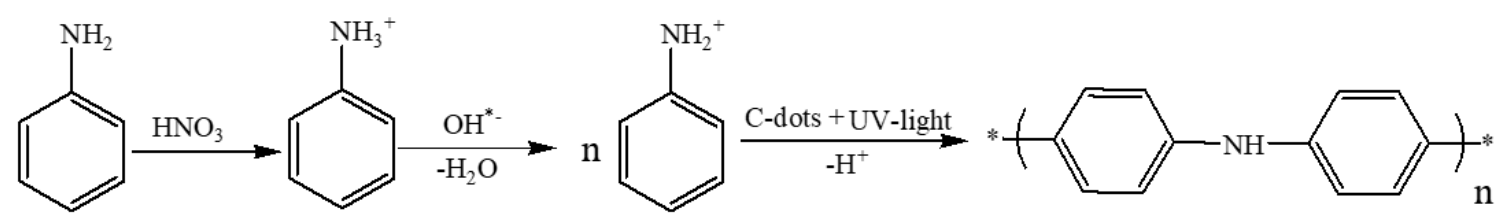

Scheme 5. Schematic representation of the electrostatic interaction between the protonated aniline and the CDs.

\section{Conclusions}

This short report provides in-depth data on the polymerization of pyrrole and its copolymer, using carbon dots as an initiator. The disadvantages and limitations in using various other initiators associated with the polymerization of pyrrole are noted, and how the use of CDs overcomes these problems is highlighted in this report. In addition, we note that both polypyrrole and copolymers were easily synthesized using only CDs as an initiator, making the polymerization low cost, non-toxic, and requiring an easy one-step preparation method. CDs are recognized as an effective and economical initiator at low concentration and can be used for polymer synthesis. The synthesized conductive polypyrrole produced using CDs has also been used in applications such as in adsorbent material for organic dyes due to its recyclable capacity, morphology, and stability. Among the available polymeric adsorbent materials, the CD-initiated polypyrrole and copolymer macro-nano materials have been widely explored as efficient adsorbent materials for the removal of different organic dyes from aqueous sources. This property has been attributed to the presence of highly active surface sites in the macro-nano adsorbents. In order to improve the performance of the CD-initiated polypyrrole, several metal oxides were used to form composites with PPY, especially for biological application. The CD-initiated polypyrrole was composited, for example, with $\mathrm{CuO}$ and demonstrated an efficient antibacterial effect against both E. coli and S. aureus. The present report thus introduces a novel polymerization method and demonstrates its advantages for PPY and its copolymers.

Funding: This research received no external funding.

Conflicts of Interest: The authors declare no conflict of interest. 


\section{References}

1. Wang, Y.; Zhu, Y.; Yu, S.; Jiang, C. RSC Advances optical properties and analytical applications. RSC Adv. 2017, 7, 40973-40989. [CrossRef]

2. Wang, Y.; Hu, A. Carbon quantum dots: Synthesis, properties and applications. J. Mater. Chem. C 2014, 2, 6921-6939. [CrossRef]

3. Li, Y.; Shu, H.; Niu, X.; Wang, J. Electronic and Optical Properties of Edge-Functionalized Graphene Quantum Dots and the Underlying Mechanism. J. Phys. Chem. C 2015, 119, 24950-24957. [CrossRef]

4. Pal, A.; Chattopadhyay, A. Conducting Carbon Dot-Polypyrrole Nanocomposite for Sensitive Detection of Picric acid. ACS Appl. Mater. Interfaces 2016, 8, 5758-5762. [CrossRef]

5. Sun, X.; Lei, Y. Trends in Analytical Chemistry. Trends Anal. Chem. 2017, 89, 163-180. [CrossRef]

6. Wang, J.; Zhang, P.; Huang, C.; Liu, G.; Leung, K.C.; Wa, J. High Performance Photoluminescent Carbon Dots for In Vitro and In Vivo Bioimaging: Effect of Nitrogen Doping Ratios. Langmuir 2015, 31, 8063-8073. [CrossRef]

7. Wang, D.; Xu, H.; Zheng, B.; Li, Y.; Liu, M.; Xiao, D. Analytical Methods selectivity for hypochlorous acid detection and its. Anal. Methods 2015, 7, 5311-5317. [CrossRef]

8. Han, C.; Wang, R.; Wang, K.; Xu, H.; Sui, M.; Li, J.; Xu, K. Biosensors and Bioelectronics Highly fl uorescent carbon dots as selective and sensitive "on-off-on" probes for iron (III) ion and apoferritin detection and imaging in living cells. Biosens. Bioelectron. 2016, 83, 229-236. [CrossRef]

9. Kumara, K.; Datta, R.; Qi, G.; Zboril, R.; Giannelis, E.P. Yellow emitting carbon dots with superior colloidal, thermal, and photochemical stabilities. J. Mater. Chem. C 2016, 4, 9798-9803.

10. Zhou, Y.; Sharma, S.K.; Peng, Z.; Leblanc, R.M. Polymers in Carbon Dots: A Review. Polymers $2017,9,67$. [CrossRef]

11. Karasik, D. Accelerated Bone Regeneration by Nitrogen-Doped Carbon Dots Functionalized with Hydroxyapatite Nanoparticles. ACS Appl. Mater. Interfaces 2018, 10, 19373-19385.

12. Abu-ghosh, S.; Bhooshan, V.; Fixler, D.; Dubinsky, Z.; Gedanken, A.; Iluz, D. Nitrogen-doped carbon dots prepared from bovine serum albumin to enhance algal astaxanthin production. Algal Res. 2017, 23, $161-165$. [CrossRef]

13. Li, H.; Kong, W.; Liu, J.; Liu, N.; Huang, H.; Liu, Y.; Kang, Z. Fluorescent N-doped carbon dots for both cellular imaging and highly-sensitive catechol detection. Carbon 2015, 91, 66-75. [CrossRef]

14. Jiang, K.; Sun, S.; Zhang, L.; Wang, Y.; Cai, C.; Lin, H. Bright-Yellow-Emissive N-Doped Carbon Dots: Preparation, Cellular Imaging, and Bifunctional Sensing. ACS Appl. Mater. Interfaces 2015, 7, 23231-23238. [CrossRef] [PubMed]

15. Qian, Z.; Ma, J.; Shan, X.; Feng, H.; Shao, L. Highly Luminescent N-Doped Carbon Quantum Dots as an Effective Multifunctional Fluorescence Sensing Platform. Chem. Eur. J. 2014, 20, 2254-2263. [CrossRef] [PubMed]

16. Khajuria, D.K.; Kumar, V.B.; Karasik, D.; Gedanken, A. Fluorescent Nanoparticles with Tissue-Dependent A ffi nity for Live Zebrafish Imaging. ACS Appl. Mater. Interfaces 2017, 9, 18557-18565. [CrossRef]

17. López, C.; Zougagh, M.; Algarra, M.; Rodríguez-Castellón, E.; Campos, B.B.; Esteves Da Silva, J.C.G.; Jiménez-Jiménez, J.; Ríos, A. Microwave-assisted synthesis of carbon dots and its potential as analysis of four heterocyclic aromatic amines. Talanta 2015, 132, 845-850. [CrossRef]

18. Lim, S.Y.; Shen, W.; Gao, Z. Carbon quantum dots and their applications. Chem. Soc. Rev. 2015, 44, 362-381. [CrossRef]

19. Liu, Y.; Liu, C.Y.; Zhang, Z.Y. Graphitized carbon dots emitting strong green photoluminescence. J. Mater. Chem. A 2013, 1, 4902-4907. [CrossRef]

20. Hola, K.; Zhang, Y.; Wang, Y.; Giannelis, E.P.; Zboril, R.; Rogach, A.L. Carbon dots—Emerging light emitters for bioimaging, cancer therapy and optoelectronics. Nano Today 2014, 9, 590-603. [CrossRef]

21. Bhooshan, V.; Gedanken, A. Facile one-step sonochemical synthesis of ultrafine and stable fluorescent C-dots. Ultrason. Sonochem. 2016, 28, 367-375.

22. Kumar, V.B.; Perelshtein, I.; Lipovsky, A.; Porat, Z.; Gedanken, A. The sonochemical synthesis of Ga@C-dots particles. RSC Adv. 2015, 5, 25533-25540. [CrossRef]

23. Innocenzi, P.; Malfatti, L.; Carboni, D. Graphene and carbon nanodots in mesoporous materials: An interactive platform for functional applications. Nanoscale 2015, 7, 12759-12772. [CrossRef] [PubMed] 
24. Fu, M.; Ehrat, F.; Wang, Y.; Milowska, K.Z.; Reckmeier, C.; Rogach, A.L.; Stolarczyk, J.K.; Urban, A.S.; Feldmann, J. Carbon Dots: A Unique Fluorescent Cocktail of Polycyclic Aromatic Hydrocarbons. Nano Lett. 2015, 15, 6030-6035. [CrossRef] [PubMed]

25. Khan, S.; Gupta, A.; Verma, N.C.; Nandi, C.K. Time-Resolved Emission Reveals Ensemble of Emissive States as the Origin of Multicolor Fluorescence in Carbon Dots. Nano Lett. 2015, 15, 8300-8305. [CrossRef] [PubMed]

26. Zheng, X.T.; Ananthanarayanan, A.; Luo, K.Q.; Chen, P. Glowing Graphene Quantum Dots and Carbon Dots: Properties, Syntheses, and Biological Applications. Small 2015, 11, 1620-1636. [CrossRef] [PubMed]

27. Xu, Q.; Kuang, T.; Liu, Y.; Cai, L.; Peng, X.; Sreeprasad, T.S.; Zhao, P.; Yu, Z.; Li, N. Heteroatom-doped carbon dots: Synthesis. J. Mater. Chem. B 2016, 4, 7204-7219. [CrossRef]

28. Sciortino, A.; Cannizzo, A.; Messina, F. Carbon Nanodots: A Review-From the Current Understanding of the Fundamental Photophysics to the Full Control of the Optical Response. Carbon 2018, 4, 67. [CrossRef]

29. Liu, M.L.; Chen, B.B.; Li, C.M.; Huang, C.Z. Carbon dots: Synthesis, formation mechanism, fluorescence origin and sensing applications. Green Chem. 2019, 21, 449-471. [CrossRef]

30. Migneault, I.; Dartiguenave, C.; Bertrand, M.J.; Waldron, K.C. Glutaraldehyde: Behavior in aqueous solution, reaction with proteins, and application to enzyme crosslinking. BioTechniques 2004, 37, 790-802. [CrossRef]

31. Chong, Y.; Ge, C.; Fang, G.; Tian, X.; Wen, T.; Wamer, W.G.; Chen, C.; Chai, Z.; Yin, J. Crossover between Antiand Pro-oxidant Activities of Graphene Quantum Dots in the Absence or Presence of Light. ACS Nano 2016, 10, 8690-8699. [CrossRef] [PubMed]

32. Sun, X.; Lei, Y. Fluorescent carbon dots and their sensing applications. TrAC 2017, 89, 163-180. [CrossRef]

33. Hu, Y.; Al Awak, M.M.; Yang, F.; Yan, S.; Xiong, Q.; Wang, P.; Tang, Y.; Yang, L.; LeCroy, G.E.; Hou, X.; et al. Photoexcited state properties of carbon dots from thermally induced functionalization of carbon nanoparticles. J. Mater. Chem. C 2016, 4, 10554-10561. [CrossRef]

34. Perelshtein, I.; Lipovsky, A.; Perkas, N.; Gedanken, A.; Moschini, E.; Mantecca, P. The influence of the crystalline nature of nano-metal oxides on their antibacterial and toxicity properties. Nano Res. 2015, 8 , 695-707. [CrossRef]

35. Monk, P.M.S.; Rosseinsky, D.R.; Mortimer, R.J. Electrochromic Materials and Devices Based on Viologens. In Electrochromic Materials and Devices; Wiley-VCH Verlag GmbH \& Co. KGaA: Weinheim, Germany, 2015; pp. 57-90. ISBN 9783527679850.

36. Chougule, M.A.; Pawar, S.G.; Godse, P.R.; Mulik, R.N.; Sen, S.; Patil, V.B. Synthesis and Characterization of Polypyrrole (PPy) Thin Films. Soft Nanosci. Lett. 2011, 1, 6-10. [CrossRef]

37. Sevilla, F. Chemical sensors based on conducting polymers. In Proceedings of the Asian Conference Sensors, 2003. AsiaSense 2003, Kebangsann, Malaysia, 18 July 2003; pp. 87-92.

38. Guimard, N.K.; Gomez, N.; Schmidt, C.E. Conducting polymers in biomedical engineering. Prog. Polym. Sci. 2007, 32, 876-921. [CrossRef]

39. Spitalsky, Z.; Tasis, D.; Papagelis, K.; Galiotis, C. Carbon nanotube-polymer composites: Chemistry, processing, mechanical and electrical properties. Prog. Polym. Sci. 2010, 35, 357-401. [CrossRef]

40. Park, K.-S.; Schougaard, S.B.; Goodenough, J.B. Conducting-Polymer/Iron-Redox- Couple Composite Cathodes for Lithium Secondary Batteries. Adv. Mater. 2007, 19, 848-851. [CrossRef]

41. Kang, H.; Geckeler, K. Enhanced electrical conductivity of polypyrrole prepared by chemical oxidative polymerization: Effect of the preparation technique and polymer additive. Polymer 2000, 41, 6931-6934. [CrossRef]

42. Li, J.; Zhang, Q.; Feng, J.; Yan, W. Synthesis of PPy-modified $\mathrm{TiO}_{2}$ composite in $\mathrm{H}_{2} \mathrm{SO}_{4}$ solution and its novel adsorption characteristics for organic dyes. Chem. Eng. J. 2013, 225, 766-775. [CrossRef]

43. Ebrahimiasl, S.; Zakaria, A.; Kassim, A.; Norleha Basri, S. Novel conductive polypyrrole/zinc oxide/chitosan bionanocomposite: Synthesis, characterization, antioxidant, and antibacterial activities. Int. J. Nanomed. 2014, 10, 217. [CrossRef] [PubMed]

44. Moorthy, M.; Kumar, V.B.; Porat, Z.; Gedanken, A. Novel polymerization of aniline and pyrrole by carbon dots. New J. Chem. 2018, 42, 535-540. [CrossRef]

45. Maruthapandi, M.; Kumar, V.B.; Gedanken, A. Carbon Dot Initiated Synthesis of Poly $\left(4,4^{\prime}-\right.$ diaminodiphenylmethane) and Its Methylene Blue Adsorption. ACS Omega 2018, 3, 7061-7068. [CrossRef] 
46. Maruthapandi, M.; Luong, H.T.; Gedanken, A. Kinetic, isotherm and mechanism studies of organic dye adsorption on poly(4,-oxybisbenzenamine) and copolymer of poly(4,-oxybisbenzenamine-pyrrole) macro-nanoparticles synthesized by multifunctional carbon dots. New J. Chem. 2019, 43, 1926-1935. [CrossRef]

47. Maruthapandi, M.; Kumar, V.B.; Luong, J.H.T.; Gedanken, A. Kinetics, Isotherm, and Thermodynamic Studies of Methylene Blue Adsorption on Polyaniline and Polypyrrole Macro-Nanoparticles Synthesized by C-Dot-Initiated Polymerization. ACS Omega 2018, 3, 7196-7203. [CrossRef]

48. Maruthapandi, M.; Nagvenkar, A.P.; Perelshtein, I.; Gedanken, A. Carbon-Dot Initiated Synthesis of Polypyrrole and Polypyrrole@CuO Micro/Nanoparticles with Enhanced Antibacterial Activity. ACS Appl. Polym. Mater. 2019, 1, 1181-1186. [CrossRef]

49. Sadki, S.; Schottland, P.; Sabouraud, G.; Brodie, N. The mechanisms of pyrrole electropolymerization. Chem. Soc. Rev 2000, 29, 283-293.

50. Liu, F.; Yuan, Y.; Li, L.; Shang, S.; Yu, X.; Zhang, Q.; Jiang, S.; Wu, Y. Synthesis of polypyrrole nanocomposites decorated with silver nanoparticles with electrocatalysis and antibacterial property. Compos. Part B Eng. 2015, 69, 232-236. [CrossRef]

51. Zhou, J.; Lü, Q.F.; Luo, J.J. Efficient removal of organic dyes from aqueous solution by rapid adsorption onto polypyrrole-based composites. J. Clean. Prod. 2018, 167, 739-748. [CrossRef]

52. Saafan, S.A. Study of Dielectric Properties of Polypyrrole Prepared using Two Different Oxidizing Agents. J. Appl. Polym. Sci. 2005, 99, 3370-3379. [CrossRef]

53. Lee, J.Y.; Kim, D.Y.; Kim, C.Y. Synthesis of soluble polypyrrole of the doped state in organic solvents. Synth. Met. 1995, 74, 103-106. [CrossRef]

54. Lin, W.; Xu, K.; Xin, M.; Peng, J.; Chen, M. Hierarchical porous polyaniline-silsesquioxane conjugated hybrids with enhanced electrochemical capacitance. RSC Adv. 2014, 4, 39508-39518. [CrossRef]

55. Patil, P.T.; Anwane, R.S.; Kondawar, S.B. Development of electrospun polyaniline/ZnO composite nanofibers for LPG sensing. Procedia Mater. Sci. 2015, 10, 195-204. [CrossRef]

56. Sapurina, I.; Blinova, N.V.; Stejskal, J.; Trchova, M. The oxidation of aniline with silver nitrate to polyaniline -Silver composites. Polymer 2009, 50, 50-56.

57. Reda, S.M.; Al-Ghannam, S.M. Synthesis and Electrical Properties of Polyaniline Composite with Silver Nanoparticles. Adv. Mater. Phys. Chem 2012, 2, 75-81. [CrossRef]

58. Ayad, M.; Zaghlol, S. Nanostructured crosslinked polyaniline with high surface area: Synthesis, characterization and adsorption for organic dye. Chem. Eng. J. 2012, 204-205, 79-86. [CrossRef]

59. Boomi, P.; Prabu, H.G.; Manisankar, P.; Ravikumar, S. Study on antibacterial activity of chemically synthesized PANI-Ag-Au nanocomposite. Appl. Surf. Sci. 2014, 300, 66-72. [CrossRef]

60. Responders, E.; Last, S.E.E. Hazardous Substance Fact Sheet; NJHealth: Ewing Township, NJ, USA, 2009.

61. Sachdev, A.; Gopinath, P. Green synthesis of multifunctional carbon dots from coriander leaves and their potential application as antioxidants, sensors and bioimaging agents. Analyst 2015, 140, 4260-4269. [CrossRef]

62. Pal, T.; Mohiyuddin, S.; Packirisamy, G. Facile and Green Synthesis of Multicolor Fluorescence Carbon Dots from Curcumin: In Vitro and in Vivo Bioimaging and Other Applications. ACS Omega 2018, 3, 831-843. [CrossRef]

63. Song, Y.; Li, H.; Lu, F.; Wang, H.; Zhang, M.; Yang, J.; Huang, J.; Huang, H.; Liu, Y.; Kang, Z. Fluorescent carbon dots with highly negative charges as a sensitive probe for real-time monitoring of bacterial viability. J. Mater. Chem. B 2017, 5, 6008-6015. [CrossRef]

64. Maruthapandi, M.; Kumar, V.B.; Levine, M.; Gedanken, A. Fabrication of poly (4,4'-oxybisbenzenamine) and its conjugated copolymers initiated by easily accessible carbon dots. Eur. Polym. J. 2018, 109, 153-161. [CrossRef]

(C) 2019 by the authors. Licensee MDPI, Basel, Switzerland. This article is an open access article distributed under the terms and conditions of the Creative Commons Attribution (CC BY) license (http://creativecommons.org/licenses/by/4.0/). 